Article

\title{
Ecophysiology of Fusarium chaquense a Novel Type A Trichothecene Producer Species Isolated from Natural Grasses
}

\author{
Maria J. Nichea ${ }^{1}$, Eugenia Cendoya ${ }^{1}$, Miriam Haidukowski ${ }^{2} \mathbb{D}$, Adriana M. Torres ${ }^{1}$ and María L. Ramirez ${ }^{1, * \mathbb{D}}$ \\ 1 Research Institute on Mycology and Mycotoxicology (IMICO), National Scientific and Technical Research \\ Council-National University of Río Cuarto (CONICET-UNRC), Río Cuarto 5800, Argentina; \\ mnichea@exa.unrc.edu.ar (M.J.N.); ecendoya@exa.unrc.edu.ar (E.C.); atorres@exa.unrc.edu.ar (A.M.T.) \\ 2 Institute of Sciences of Food Production, CNR, 70126 Bari, Italy; miriam.haidukowski@ispa.cnr.it \\ * Correspondence: mramirez@exa.unrc.edu.ar; Tel.: +54-358-4676429; Fax: +54-358-4676231
}

check for

updates

Citation: Nichea, M.J.; Cendoya, E.; Haidukowski, M.; Torres, A.M.; Ramirez, M.L. Ecophysiology of Fusarium chaquense a Novel Type A Trichothecene Producer Species Isolated from Natural Grasses. Toxins 2021, 13, 895. https://doi.org/ $10.3390 /$ toxins 13120895

Received: 11 October 2021 Accepted: 8 November 2021 Published: 13 December 2021

Publisher's Note: MDPI stays neutral with regard to jurisdictional claims in published maps and institutional affiliations.

Copyright: (c) 2021 by the authors. Licensee MDPI, Basel, Switzerland. This article is an open access article distributed under the terms and conditions of the Creative Commons Attribution (CC BY) license (https:/ / creativecommons.org/licenses/by/ $4.0 /)$.
Abstract: Fusarium chaquense, a recently formally described novel species, has been identified as an T-2 toxin (T-2), HT-2 toxin (HT-2) and other toxins producer in natural grasses (Poaceae) from Argentina. The major objective of this study was to describe the effect of water activity $\left(\mathrm{a}_{\mathrm{W}}, 0.995,0.98\right.$, $0.95,0.93$ and 0.91$)$, temperature $\left(15,25\right.$ and $\left.30^{\circ} \mathrm{C}\right)$ and incubation time $(5,15$ and 25 days) on growth and to evaluate the production of T-2, HT-2 toxins and beauvericin (BEA) by two F. chaquense strains in a grass-based media. The results showed a wide range of conditions for $F$. chaquense growth and mycotoxin production. Both strains had a maximum growth rate at the highest $\mathrm{a}_{\mathrm{W}}(0.995)$ and $25^{\circ} \mathrm{C}$. Regarding mycotoxin production, more T-2 than the other analysed mycotoxins were produced by the two strains. T-2 production was favoured at $0.995 \mathrm{aw}$ and $30{ }^{\circ} \mathrm{C}$, while HT-2 production at $0.98-0.95 \mathrm{a}_{\mathrm{W}}$ and $15{ }^{\circ} \mathrm{C}$. The maximum levels of BEA were produced at $0.995 \mathrm{a}_{\mathrm{W}}$ and $25-30{ }^{\circ} \mathrm{C}$. Two-dimensional profiles of $\mathrm{a}_{\mathrm{W}}$ by temperature interactions were obtained from these data in order to identify areas where conditions indicate a significant risk of mycotoxins accumulation on grass. For its versatility on growth and mycotoxin production in a wide range of $\mathrm{a}_{\mathrm{W}}$ and temperatures, F. chaquense would have an adaptive advantage over other Fusarium species, and this would explain its high frequency of isolation in natural grasses grown up in the Chaco wetlands.

Keywords: Fusarium chaquense; Poaceae; ecophysiology; beauvericin; trichothecenes

Key Contribution: Deep ecophysiological characterisation of a recently described Fusarium species F. chaquense, a novel member of the FSAMSC type A trichothecene producer isolated from asymptomatic native grasses. From this study, it can be concluded that $F$. chaquense appears to be very versatile as it can grow and produce mycotoxins in a wide range of $\mathrm{a}_{\mathrm{W}}$ and temperatures, which would give it an adaptive advantage over other Fusarium species, and this would explain its high frequency of isolation in natural grasses growing in this wetland ecosystem.

\section{Introduction}

Fusarium chaquense is a recently described species isolated from asymptomatic native grasses (Poaceae) from a wetland ecosystem of the Chaco Province, Argentina, intended for grazing cattle. DNA sequence-based phylogenetic analyses indicated that F. chaquense is closely related to F. armeniacum and nested within a clade of primarily type A trichothecene-producing species of the Fusarium sambucinum species complex (FSAMSC) [1] This clade included F. armeniacum, F. langsethiae, F. sibiricum, F. sporotrichioides, F. palustre and F. goolgardi, which are among the few species that produce type A trichothecenes that have an acyl (e.g., T-2 toxin) or hydroxyl (e.g., neosolaniol) group at C8 and no oxygen atom at $C 7[2,3]$. The analysis of genome sequences also revealed that $F$. chaquense has genes required for trichothecene biosynthesis. In chemical analysis, F. chaquense isolates produced the type A trichothecenes T-2 toxin (T-2) and HT-2 toxin (HT-2), neosolaniol (NEO), diacetoxyscirpenol (DAS) and monoacetoxyscirpenol (MAS), as well as the mycotoxin 
beauvericin (BEA) and the pigment aurofusarin (AUF). None of the F. chaquense isolates examined produced any known type $B$ trichothecenes [1]. These novel species were recovered as part of a previous analysis of 175 grass samples representative of 12 genera of the family Poaceae from an area known as Chaco Wetlands (Ramsar site no. $1366,27^{\circ} 20^{\prime} \mathrm{S} 058^{\circ} 50^{\prime} \mathrm{W}$ ) intended to graze cattle, during 2011 and 2014. All the samples were contaminated with mycotoxins, including zearalenone (ZEA), which was present at up to $2000 \mu \mathrm{g} / \mathrm{kg}$, and the type A trichothecenes T-2 and HT-2, which were each present at up to $5000 \mu \mathrm{g} / \mathrm{kg}$ [4] Other fungal metabolites detected in the grass samples included the mycotoxins BEA and equisetin and the pigment AUF [4]. Mycological analysis revealed that $100 \%$ of sampled plants were infected with Fusarium, with F. chaquense being the most common species found $(61 \%)$. These findings indicate that $F$. chaquense is a likely source of observed contamination of Chaco wetland grasses with type A trichothecenes [4]. In contrast, the F. chaquense isolates examined by Nichea et al. [1] did not produce the mycotoxin ZEA, and they did not have ZEA biosynthetic genes in their genome sequences. Therefore, the contamination of Chaco wetland grasses with ZEA, as reported by Nichea et al. [1], was almost certainly caused by another fungal species.

Recently Laraba et al. [5] conducted a study about the diversity and trichothecene potential of selected strains belonging to the FSAMSC in order to analyse the phylogenetic diversity of this species complex. Nichea et al. [1] compared partial RPB2 and TEF1 sequences of some $F$. chaquense strains with the aforementioned study and indicated that they are $100 \%$ identical to another phylogenetically but not formally described species, Fusarium sp. nov.-1. This indicates that $F$. chaquense and Fusarium sp. nov.-1 are conspecific (Fusarium sp. nov.-1 is hereafter referred to as F. chaquense). One of the two F. chaquense isolates examined by Laraba et al. [5] was recovered from the soil in Australia, and the other was from oats in South Africa. The isolation of F. chaquense from sources in Argentina, Australia and South Africa indicates that the species has a relatively wide distribution in the Southern Hemisphere [1].

Trichothecenes represent one of the major classes of mycotoxins, and they cause a significant economic impact on cereal crops each year [6,7]. Over 200 trichothecene analogs have been identified, all of which share the tricyclic 12,13-epoxytrichothec-9-ene (EPT) core structure [8]. These analogs were classified into four groups (Types A, B, C and D) based on the substitution pattern of EPT. Based on the substitution at the C-8 position, types A, B and $C$ trichothecenes can be differentiated [9]. Type $A$ trichothecenes include compounds that have a hydroxyl group at C-8 (e.g., NEO), an ester function at C-8 (e.g., T-2) or no oxygen substitution at C-8 (e.g., DAS). Type A trichothecenes are highly toxic to animals; they cause immune disorders, weight loss, growth retardation, pathological changes in liver cells and death. Moreover, these toxins can inhibit mitosis, nucleic acids and proteins synthesis, as well as induce apoptosis. In plants, DAS and T-2 toxins can cause chlorosis and inhibit coleoptile and root elongation [6].

It is well known that fungal growth and mycotoxin production are a result of the complex interaction of several factors; thus, understanding each factor is essential to understand the overall process to predict and prevent mycotoxin development [10]. Water activity $\left(\mathrm{a}_{\mathrm{W}}\right)$ and temperature are the primary environmental factors that influence growth and mycotoxin production by several Fusarium species [11].

Scarce information about the ecology of Fusarium species in natural ecosystems is available, although surveys in the USA and Australia suggest that Fusarium species are commonly found in poaceas in grassland ecosystems [12-14]. Moreover, it is important to remark that $F$. chaquense was also isolated from oats in South Africa, with this cereal being susceptible to trichothecene contamination. As part of $F$. chaquense characterisation, we consider it important to study the impact of water activity $\left(\mathrm{a}_{W}\right)$ and temperature on growth and mycotoxins production (T-2, HT-2 and BEA) by two strains of $F$. chaquense isolated from natural grasses. The results obtained from this type of study allow the identification of climate conditions that could indicate a significant risk of mycotoxin accumulation on grasses. As F. chaquense is associated with natural grasses in Argentina intended for cattle 
consumption, their contamination with mycotoxins should not be underestimated in order to preserve animal health.

\section{Results}

\subsection{Effect of Water Activity and Temperature on Lag Phase and Growth}

The effect of temperature and $\mathrm{a}_{\mathrm{W}}$ on $F$. chaquense lag phase is shown in Figure 1. In general, both strains showed similar behaviour. The lag phase increased when temperature and $a_{W}$ decreased. Lag phases were shorter $(<24 \mathrm{~h})$ at 0.995 and 0.98 at all temperatures analysed. Lag phases increased considerably at the lowest temperature studied $\left(15^{\circ} \mathrm{C}\right)$ and at low aw levels.

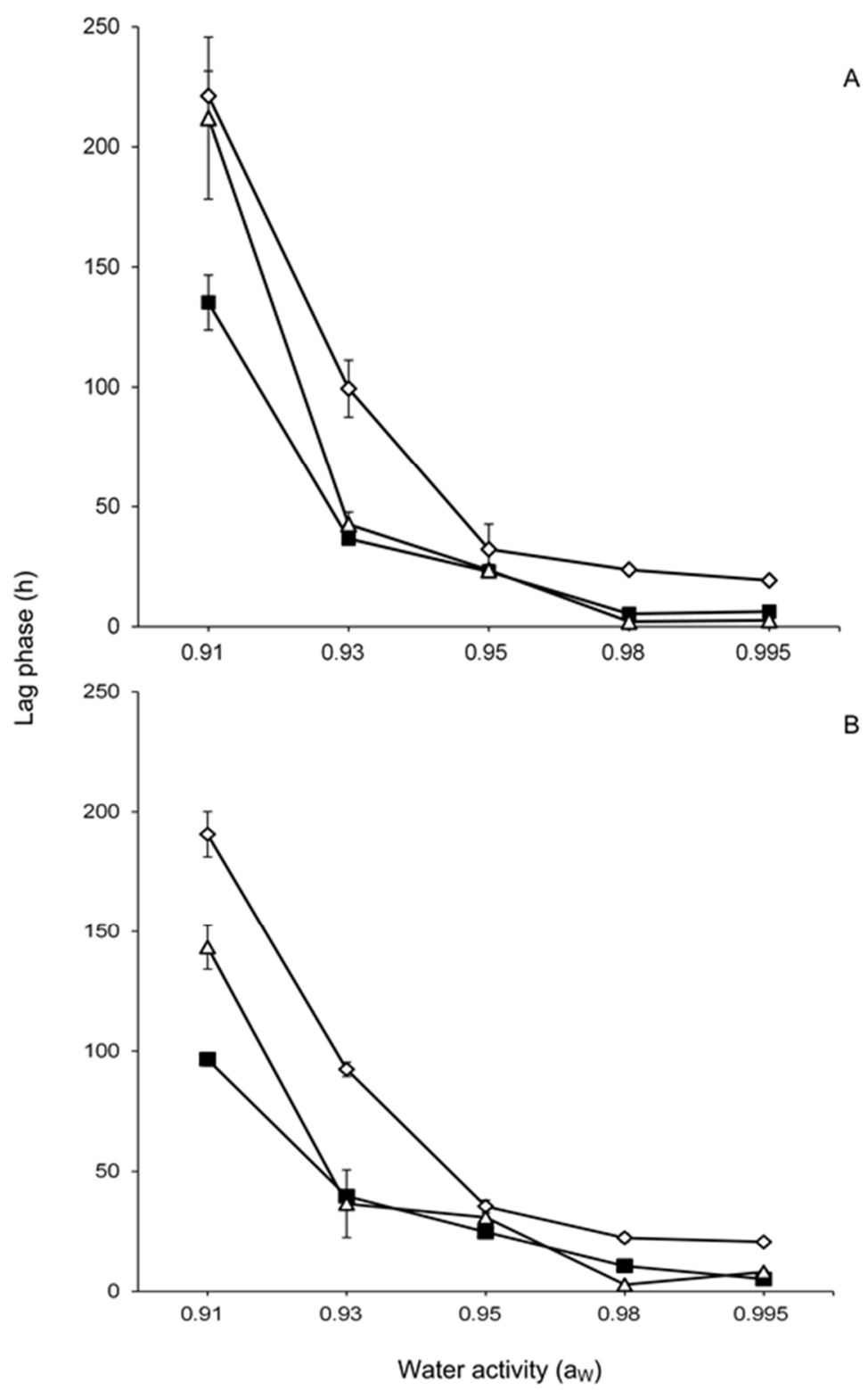

Figure 1. Effect of water activity (0.91-0.995) and temperature $15{ }^{\circ} \mathrm{C}(\diamond), 25{ }^{\circ} \mathrm{C}(\boldsymbol{\square}), 30{ }^{\circ} \mathrm{C}(\triangle)$ on lag phase of two Fusarium chaquense strains in the grass-based culture media (A: NRRL 66748; B: NRRL 66749). The error bars represent the standard deviation for the triplicates.

Figure 2 compares the interaction between $\mathrm{a}_{\mathrm{W}}$ and temperature on growth rates of two F. chaquense strains grown in a grass-based media. Both strains showed similar behaviour, and they were able to grow at $\mathrm{a}_{\mathrm{W}}$ levels ranging from 0.995 to 0.91 at $15-30{ }^{\circ} \mathrm{C}$ with 
maximum growth rates obtained at the highest $\mathrm{a}_{\mathrm{W}}(0.995)$ and $25^{\circ} \mathrm{C}$. Growth of both strains decreased as $\mathrm{a}_{\mathrm{W}}$ of the media was reduced. Regarding incubation temperature, the highest growth rates were obtained at $25^{\circ} \mathrm{C}$, decreasing in the following order: 30 and $15^{\circ} \mathrm{C}$, regardless of $\mathrm{a}_{\mathrm{W}}$. The two strains were able to grow at the lowest $\mathrm{a}_{\mathrm{W}}$ tested (0.91) at the three assayed temperatures.

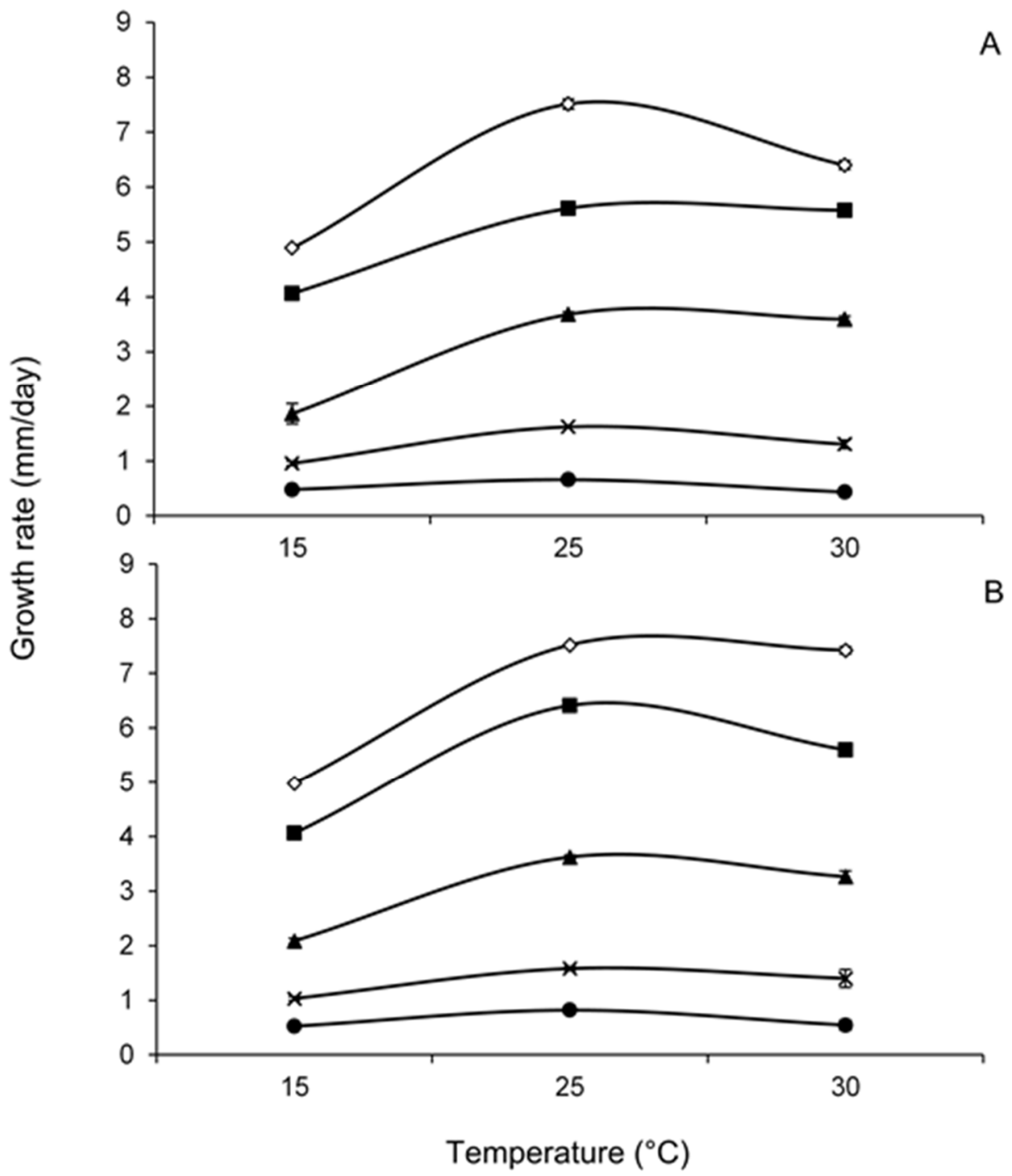

Figure 2. Effect of water activity, $0.91(\bullet), 0.93(\mathrm{X}), 0.95(\boldsymbol{\Delta}), 0.98(\mathbf{\square}), 0.995(\diamond)$ and temperature on growth rate of two Fusarium chaquense strains in the grass-based culture (A: NRRL 66748; B: NRRL 66749). The error bars represent the standard deviation for the triplicates.

The analysis of variance separately performed in order to analyse the effect of the single variables considered in the study (strain, $a_{W}$, temperature) and two- and three-way interactions revealed that all variables alone and all interactions had a significant effect on lag phases and growth rates. The most significant variable was $a_{\mathrm{W}}$ for lag phases and strain $\mathrm{x} \mathrm{a}_{\mathrm{W}}$ interaction for growth rates (Table 1). 
Table 1. Analysis of variance on the effect of water activity $\left(a_{W}\right)$, temperature $(T)$ and different strains $(S)$ and their interactions on growth rates and lag phases of Fusarium chaquense grown in a grass-based media.

\begin{tabular}{lccccc}
\hline \multirow{2}{*}{$\begin{array}{l}\text { Source of } \\
\text { Variation }\end{array}$} & Df $^{\mathbf{a}}$ & \multicolumn{2}{c}{ Lag Phase (h) } & \multicolumn{2}{c}{ Growth Rate (mm/day) } \\
\cline { 3 - 6 } & & $\mathbf{M S}^{\mathbf{b}}$ & $\mathbf{F}^{\mathbf{c}}$ & MS & $\mathbf{F}$ \\
\hline $\mathrm{S}$ & 1 & 0.01 & $31.85^{*}$ & 30.66 & $831.09^{*}$ \\
$\mathrm{~T}$ & 2 & 0.11 & $241.97^{*}$ & 0.09 & $23.63^{*}$ \\
$\mathrm{a}_{\mathrm{W}}$ & 4 & 0.14 & $307.61^{*}$ & 0.63 & $168.57^{*}$ \\
$\mathrm{~S} \times \mathrm{T}$ & 2 & 0.01 & $19.79 *$ & 1.08 & $288.61^{*}$ \\
$\mathrm{~S} \times \mathrm{a}_{\mathrm{W}}$ & 4 & 0.01 & $15.19^{*}$ & 13.41 & $3585.19^{*}$ \\
$\mathrm{~T} \times \mathrm{a}_{\mathrm{W}}$ & 8 & 0.04 & $98.41^{*}$ & 0.03 & $7.42^{*}$ \\
$\mathrm{~S} \times \mathrm{T} \times \mathrm{a}_{\mathrm{W}}$ & 8 & 0.01 & $17.38^{*}$ & 0.10 & $25.91^{*}$ \\
\hline
\end{tabular}

* Significant $p<0.01 .{ }^{\text {a }}$ Degrees of freedom. ${ }^{\mathrm{b}}$ Mean square. ${ }^{\mathrm{c}}$ Snedecor-F.

Contour lines to map the relative optimum and marginal conditions that allowed F. chaquense growth were performed (Figure 3). These contour maps show that the growth rate ranged from 0.995 to $0.95 \mathrm{a}_{\mathrm{W}}$ at $25-30{ }^{\circ} \mathrm{C}$, indicating possible optimum conditions for growth for both $F$. chaquense strains.

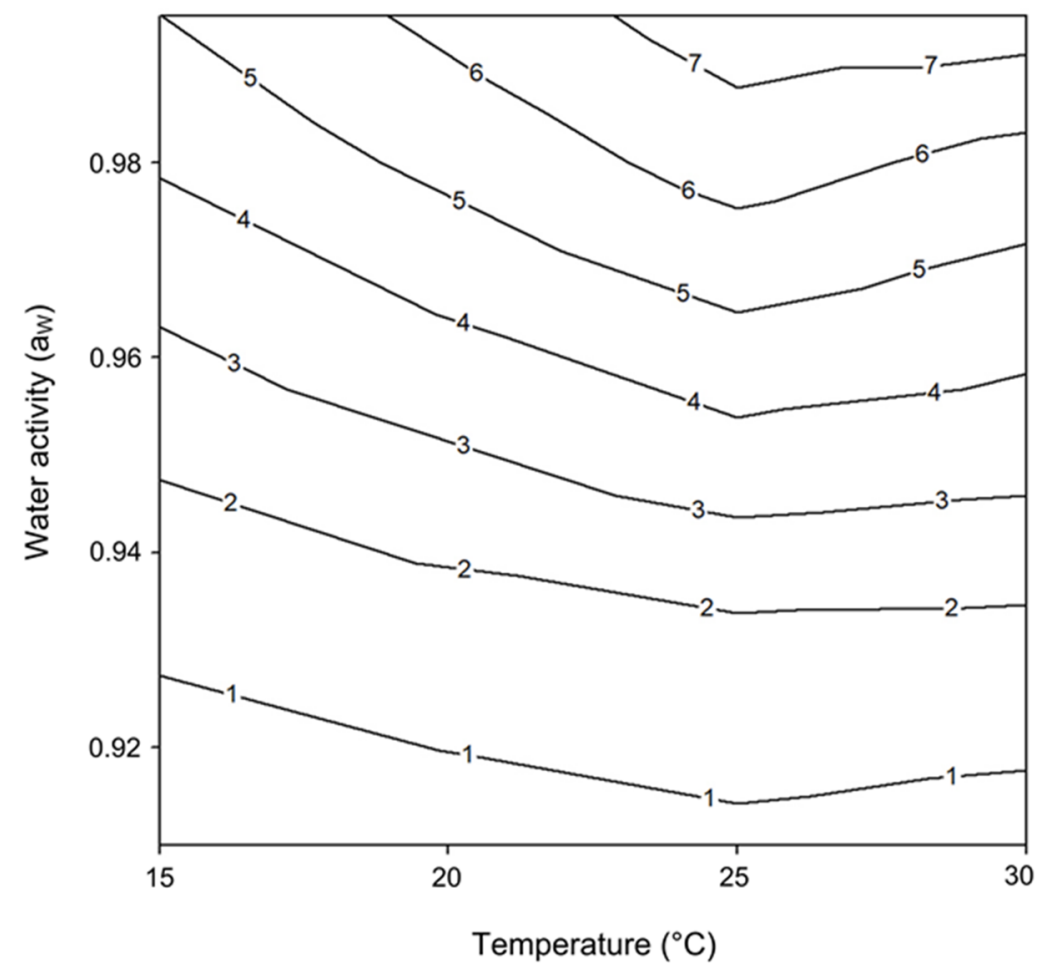

Figure 3. Two-dimensional contour map of Fusarium chaquense growth profile in relation to temperature and water activity. The numbers on the isopleths refer to similar growth rates (mm/day).

\subsection{Effect of $a_{W}$, Temperature and Incubation Time on Mycotoxin Production}

Figure 4 shows the effect of $\mathrm{a}_{\mathrm{W}}$, temperature and incubation time on T-2, HT-2 and BEA production by both strains of $F$. chaquense grown in a grass-based media over 25 days.

Maximum T-2 levels were produced by both strains at 0.995 aw and $30{ }^{\circ} \mathrm{C}$ after 5 days of incubation. Overall, strain NRRL 66749 produced more T-2 than strain NRRL 66748 under the same conditions, 84.2 and $70.5 \mu \mathrm{g} / \mathrm{g}$, respectively. T-2 production was higher at $30{ }^{\circ} \mathrm{C}$, decreasing in the following order: 15 and $25{ }^{\circ} \mathrm{C}$ for both strains. At $25^{\circ} \mathrm{C}$, maximum amounts of T-2 were obtained at $0.995 \mathrm{a}_{\mathrm{W}}$ after 5 days of incubation for F. chaquense NRRL 66748, while for F. chaquense NRRL 66749, it was at 0.95 aw after 15 days of incubation. At $15{ }^{\circ} \mathrm{C}$, maximum amounts of T-2 were obtained at 0.98 aw after 25 days of incubation for both $F$. chaquense strains. 


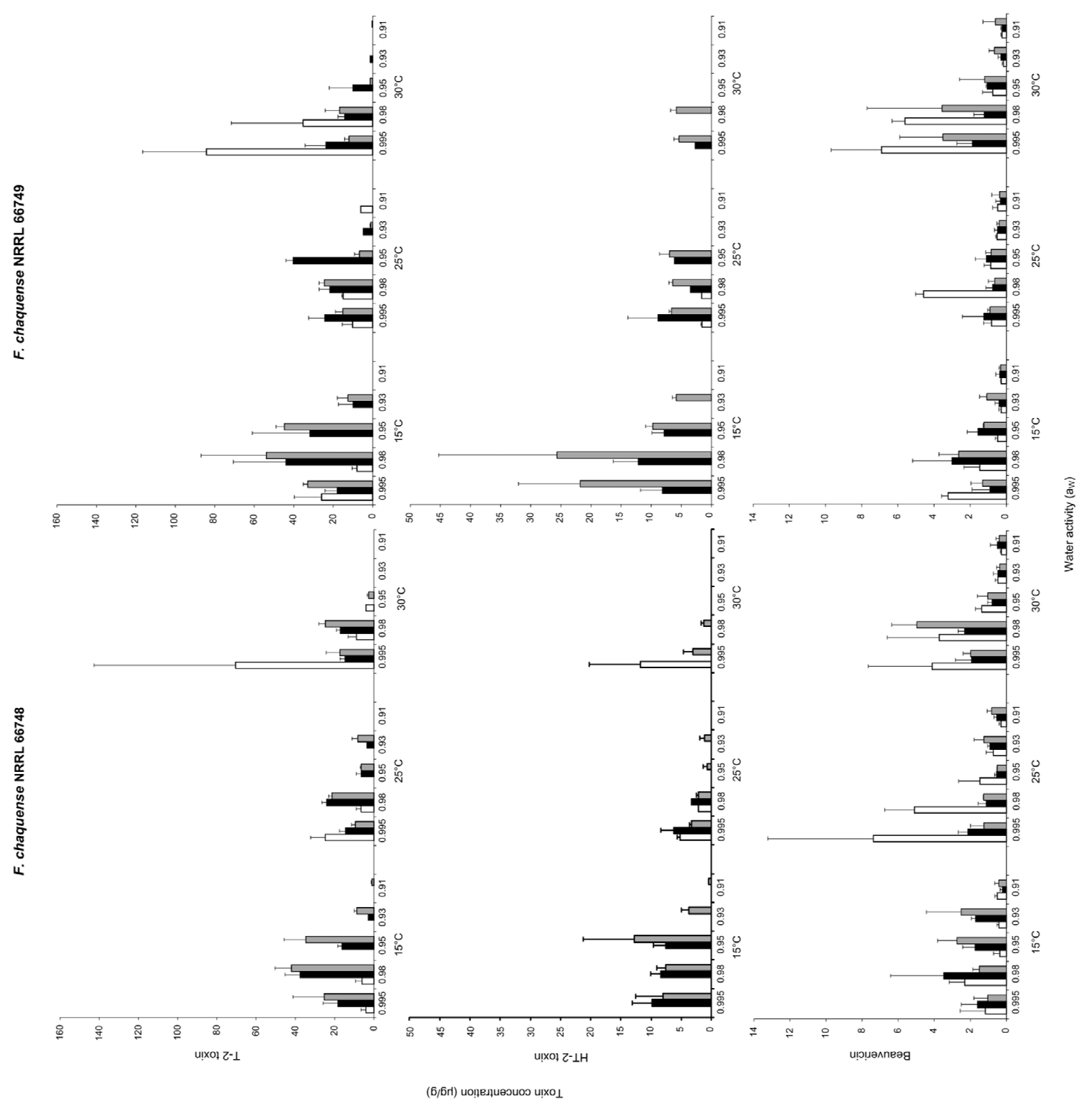

Figure 4. Toxins concentrations T-2, HT-2 and BEA ( $\mu \mathrm{g} / \mathrm{g})$ produced by Fusarium chaquense strains NRRL 66748 and NRRL 66749 in the grass-based culture adjusted to different $\mathrm{a}_{\mathrm{W}}$ levels and temperatures at different incubated times. 5 ( $\square$ ), 15 (ם) and 25 (口) days.

The analysis of variance showed that T-2 production was significantly affected by $\mathrm{a}_{\mathrm{W}}$, temperature $\mathrm{x}$ incubation time and $\mathrm{a}_{\mathrm{W}} \mathrm{x}$ incubation time interactions for $F$. chaquense NRRL 66748. While for $F$. chaquense NRRL 66749, aw, time of incubation and $a_{W} x$ time of incubation interaction significantly influenced T-2 production, with $\mathrm{a}_{\mathrm{W}}$ being the most important variable affecting T-2 production for both strains.

The highest production level of HT-2 was observed at $15^{\circ} \mathrm{C}$ and 25 days of incubation for both strains, but at different $\mathrm{a}_{\mathrm{W}}: 0.95$ and 0.98 for strain NRRL 66748 and NRRL 66749, respectively. Overall, strain NRRL 66749 produced more HT-2 than strain NRRL 66748 under the same conditions, 25.6 and $12.8 \mu \mathrm{g} / \mathrm{g}$, respectively. HT-2 production was higher at $15{ }^{\circ} \mathrm{C}$, decreasing in the following order: 25 and $30^{\circ} \mathrm{C}$ for both strains. At $30^{\circ} \mathrm{C}$, no toxin production was detected when $\mathrm{a}_{\mathrm{W}}$ values were lower than 0.98 for any strain. At $25^{\circ} \mathrm{C}$, the maximum levels were obtained at $0.995 \mathrm{a}_{\mathrm{W}}$ after 15 days of incubation for both strains. While, at $15^{\circ} \mathrm{C}$, the maximum levels were obtained after 15 days of incubation, but at $0.95 \mathrm{a}_{\mathrm{W}}$ and $0.98 \mathrm{a}_{\mathrm{W}}$ for F. chaquense NRRL 66748 and NRRL 66749, respectively. 
The analysis of variance of the HT-2 data showed that, for both strains, all the individual factors and some interactions significantly influenced the production of the toxin. $a_{W}$ and incubation were the most important factors for NRRL 66748 and NRRL 66749 strains, respectively (Table 2).

Table 2. Analysis of variance on the effects of water activity $\left(a_{W}\right)$, temperature $(T)$, incubation time (D) and their interactions on three mycotoxin production by Fusarium chaquense strains grown in a grass-based media.

\begin{tabular}{|c|c|c|c|c|c|c|c|}
\hline \multicolumn{8}{|l|}{ NRRL 66748} \\
\hline \multirow{2}{*}{ Source of variation } & \multirow{2}{*}{$D f^{a}$} & \multicolumn{2}{|c|}{$\mathrm{T}-2$} & \multicolumn{2}{|c|}{ HT-2 } & \multicolumn{2}{|c|}{ BEA } \\
\hline & & $\mathbf{M S}^{\mathbf{b}}$ & $\mathbf{F}^{\mathrm{c}}$ & MS & F & MS & $\mathbf{F}$ \\
\hline $\mathrm{T}$ & 2 & 188.37 & 1.32 & 59.04 & $14.62 *$ & 0.01 & 0.12 \\
\hline$a_{W}$ & 4 & 2938.12 & 20.64 * & 72.81 & $18.03 *$ & 3.14 & 31.28 * \\
\hline $\mathrm{D}$ & 2 & 220.05 & 1.55 & 24.29 & $6.01 *$ & 0.12 & 1.22 \\
\hline $\mathrm{T} \times \mathrm{a}_{\mathrm{W}}$ & 8 & 363.2 & 2.55 & 10.57 & $2.62 *$ & 0.44 & $4.36^{*}$ \\
\hline $\mathrm{T} \times \mathrm{D}$ & 4 & 722.38 & $5.07 *$ & 41.1 & $10.18^{*}$ & 0.66 & $6.52 *$ \\
\hline$a_{W} \times D$ & 8 & 558.43 & $3.92 *$ & 6.38 & 1.58 & 0.33 & 3.24 * \\
\hline $\mathrm{T} \times \mathrm{a}_{\mathrm{W}} \times \mathrm{D}$ & 16 & 228.5 & 1.61 & 11.12 & $2.75 *$ & 0.24 & $2.41 *$ \\
\hline \multicolumn{8}{|l|}{ NRRL 66749} \\
\hline \multirow{2}{*}{ Source of variation } & \multirow{2}{*}{$D f^{a}$} & \multicolumn{2}{|c|}{$\mathrm{T}-2$} & \multicolumn{2}{|c|}{ HT-2 } & \multicolumn{2}{|c|}{ BEA } \\
\hline & & $\mathbf{M S}^{\mathbf{b}}$ & $\mathbf{F}^{\mathrm{c}}$ & MS & $\mathbf{F}$ & MS & $\mathbf{F}$ \\
\hline $\mathrm{T}$ & 2 & 1.02 & 7.26 & 9.13 & $30.46 *$ & 0.3 & 2.73 \\
\hline$a_{W}$ & 4 & 7.03 & 49.84 * & 7.6 & 25.37 & 3.48 & $31.46^{*}$ \\
\hline $\mathrm{D}$ & 2 & 1.21 & $8.54 *$ & 14.96 & $49.91 *$ & 0.2 & 1.85 \\
\hline $\mathrm{T} \times \mathrm{a}_{\mathrm{W}}$ & 8 & 0.3 & 2.11 & 0.86 & 2.87 & 0.4 & 3.60 * \\
\hline $\mathrm{T} \times \mathrm{D}$ & 4 & 0.4 & 2.82 & 2.56 & 8.55 & 0.2 & 1.85 \\
\hline$a_{W} \times D$ & 8 & 0.71 & $5.05 *$ & 1.97 & 6.59 & 0.3 & $2.75 *$ \\
\hline $\mathrm{T} \times \mathrm{a}_{\mathrm{W}} \times \mathrm{D}$ & 16 & 0.12 & 0.88 & 0.57 & 1.9 & 0.25 & $2.25 *$ \\
\hline
\end{tabular}

* Significant $p<0.01 .{ }^{a}$ Degrees of freedom. ${ }^{\mathrm{b}}$ Mean square. ${ }^{\mathrm{c}}$ Snedecor-F.

Maximum BEA levels were produced by both strains at $0.995 \mathrm{a}_{\mathrm{W}}$ after 5 days of incubation, but at different temperatures: $25^{\circ} \mathrm{C}$ and $30{ }^{\circ} \mathrm{C}$ for strain NRRL 66748 and NRRL 66749, respectively. Overall, both strains produced similar levels under the same conditions $(7.4$ and $6.9 \mu \mathrm{g} / \mathrm{g})$. BEA production was higher at $30{ }^{\circ} \mathrm{C}$, decreasing in the following order: 25 and $15^{\circ} \mathrm{C}$ for strain NRRL 66749. Furthermore, for strain NRRL 66748, BEA production was higher at $25^{\circ} \mathrm{C}$, decreasing in the following order: $30{ }^{\circ} \mathrm{C}$ and $15{ }^{\circ} \mathrm{C}$.

At the highest temperature assayed $\left(30^{\circ} \mathrm{C}\right)$, the strains differed in the $\mathrm{a}_{W}$ for maximum BEA production, being 0.98 and 0.995 after 5 days of incubation for the strain NRRL 66748 and NRRL 66749, respectively. At $25^{\circ} \mathrm{C}$, the maximum levels were obtained after 5 days of incubation, but at $0.995 \mathrm{a}_{\mathrm{W}}$ and $0.98 \mathrm{a}_{\mathrm{W}}$ for F. chaquense NRRL 66748 and NRRL 66749, respectively. At $15{ }^{\circ} \mathrm{C}$, the maximum amount of BEA was observed at 0.98 aW after 15 days of incubation for F. chaquense NRRL 66748. While for F. chaquense NRRL 66749, the maximum amount of BEA was observed at 0.995 after 5 days of incubation.

The analysis of variance indicated that, for both strains, BEA production was significantly affected by $\mathrm{a}_{\mathrm{W}}$ and two- and three-way interactions (except temperatures $\mathrm{x}$ days of incubation by strain NRRL 66749). aw was the most important factor for both strains (Table 2).

\subsection{Effect of $a_{W}$ and Temperature on Mycotoxin Profiles}

Figure 5 shows the two-dimensional contour maps obtained in order to identify the optimum conditions of $\mathrm{a}_{\mathrm{W}}$, temperature and the range of conditions for the production of different amounts of mycotoxins by F. chaquense. Both strains of F. chaquense evaluated produced higher levels of T-2 at $0.995 \mathrm{a}_{\mathrm{W}}$ and $30^{\circ} \mathrm{C}$. Moreover, both strains produced appreciable levels of T-2 at $0.98 \mathrm{a}_{\mathrm{W}}$ and $15^{\circ} \mathrm{C}$. HT-2 showed the maximum level at $0.98-0.95 \mathrm{a}_{\mathrm{W}}$ and $15^{\circ} \mathrm{C}$. Finally, for BEA, maximum levels were obtained at 0.98-0.995 aw and $25-30{ }^{\circ} \mathrm{C}$. 

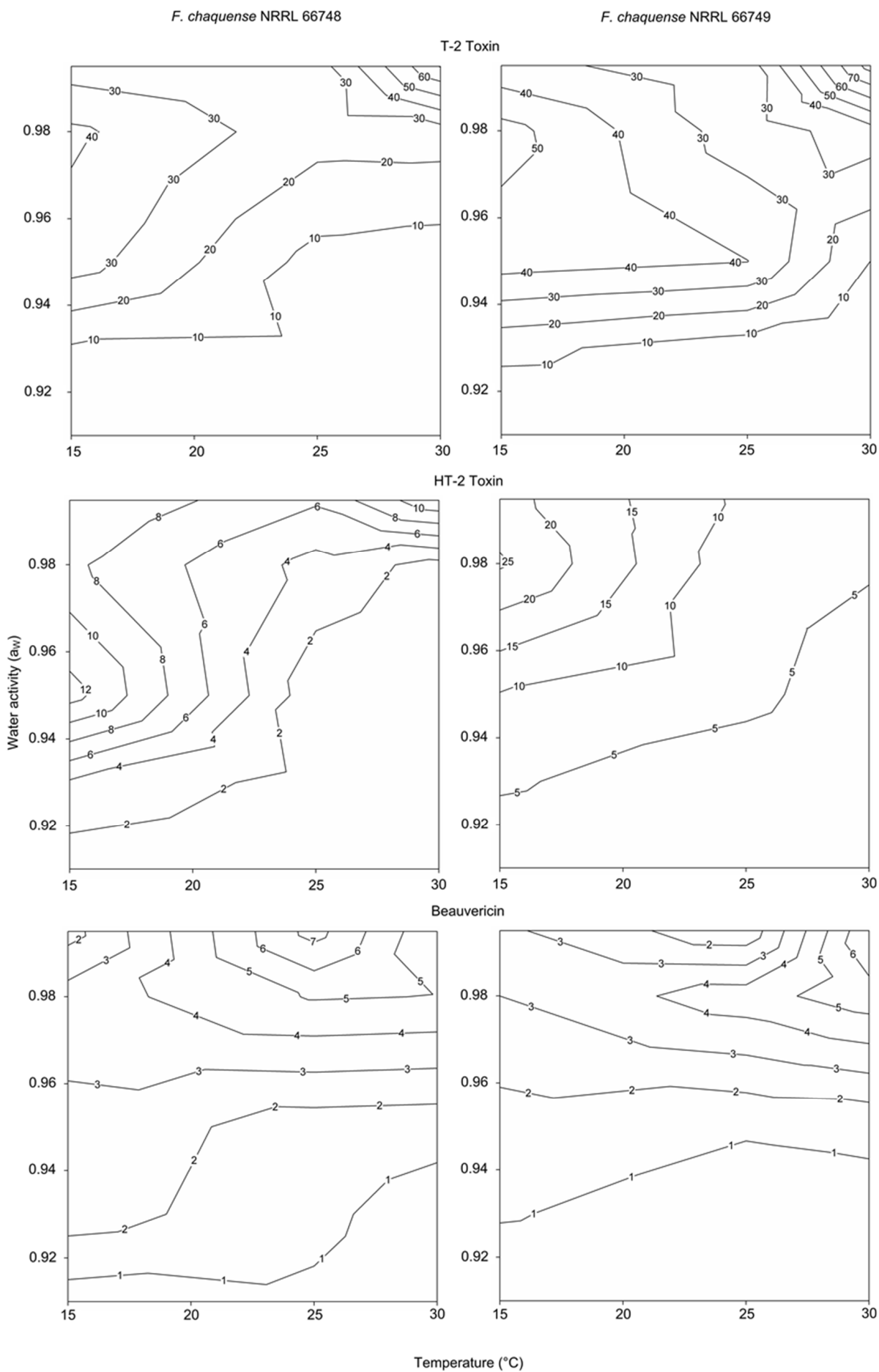

Figure 5. Two-dimensional contour maps of T-2, HT-2 and BEA production of Fusarium chaquense NRRL 66748 and NRRL 66749 in relation to temperature and water activity. The numbers on the isopleths refer to toxin levels $(\mu \mathrm{g} / \mathrm{g})$.

\section{Discussion}

The FSAMSC represent one of the most taxonomically challenging groups of fusaria, comprising important mycotoxigenic plant pathogens as well as other species with various way of life. Among other toxins produced by members belonging to the FSAMSC, trichothecenes propose the most significant threat to public health [5]. Recently we described a novel member of the FSAMSC, F. chaquense isolated from asymptomatic native grasses (Poaceae) from a wetland ecosystem of the Chaco Province, Argentina. As part of this 
species characterisation, we conducted the present study in order to perform a deep analysis of the important type A trichothecene producer. From this study, it can be concluded that F. chaquense was able to grow in a grass-based media at almost all evaluated conditions: $\mathrm{a}_{\mathrm{W}}$ values from 0.90 to 0.995 , and three temperatures, 15,25 and $30^{\circ} \mathrm{C}$. Lag phases results were similar to those previously discussed by Medina and Magan [15] in other Fusarium species.

Previous studies were performed on Fusarium species such as F. langsethiae, F. sporotrichioides and other species members of the FSAMSC, a lineage of Fusarium that produces trichothecene mycotoxins [16-19]. The results of the current study demonstrated that F. chaquense strains maximum growth ranged from 25 to $30{ }^{\circ} \mathrm{C}$ at $0.995 \mathrm{a}_{\mathrm{W}}$, reflecting the local climatic conditions of this species isolation region of Chaco wetlands. In this region, the annual temperature ranges between 20 and $24^{\circ} \mathrm{C}$. Maximum absolute temperatures can peak at $46.5^{\circ} \mathrm{C}$, and mean annual rainfall is $1300 \mathrm{~mm}$, concentrated in spring and summer [20]. Growth was observed at the lowest assayed $\mathrm{a}_{\mathrm{W}}(0.90)$ at all tested temperatures.

In previous studies, Kokkonen et al. [18] reported that species related to F. chaquense, such as F. langsethiae and F. sporotrichoides, were able to grow in an oat-based media with the maximal growth observed at $25^{\circ} \mathrm{C}$ and 0.995 and $0.98 \mathrm{a}_{\mathrm{W}}$. Although, F. sporotrichioides can occur under a wider range of water stress conditions ( $a_{W} 0.95$ and 0.93 ) than F. langsethiae. These results were similar to those reported by Medina and Magan [15], who studied the growth of $F$. langsethiae strains isolated from different northern European countries and also demonstrated that maximum growth was at $25{ }^{\circ} \mathrm{C}$ and 0.995 and $0.98 \mathrm{aw}$. In general, the present work results obtained were similar to those. Considering that Fusarium species can persist on a substrate during long periods of time, where $\mathrm{a}_{\mathrm{W}}$ may change and temperature fluctuations may occur, the knowledge of optimal aw and temperature range for growth is important. Moreover, in the field, the colonisation of developing grass by F. chaquense can be influenced by changes in relative humidity, temperature and rainfall.

Regarding mycotoxin production, in general, the maximum toxin levels were produced at different conditions than those optimal for $F$. chaquense growth. The mycotoxin production profile of both $F$. chaquense strains were in the order of importance: T-2, HT-2 and BEA. Fusarium chaquense mycotoxin production profile results similar to those previously described for F. langsethiae and F. sporotrichioides [21-23], which is the T-2 toxin, the type A trichothecene produced in the highest concentration by this species. However, the production of BEA by F. langsethiae and F. sporotrichioides has not been studied in depth. Our data show that trichothecenes synthesis predominates over BEA due to trichothecenes being detected in higher levels, at least under the assayed conditions of the present study.

The present study showed that the maximum T-2 level was produced by both strains at $0.995 \mathrm{a}_{\mathrm{W}}$ and $30{ }^{\circ} \mathrm{C}$ after 5 days of incubation, followed by at $0.98 \mathrm{a}_{\mathrm{W}}$ and $15^{\circ} \mathrm{C}$ after 25 days of incubation. With regard to the other type A trichothecene studied, the highest level of HT-2 was obtained at $0.98-0.95 \mathrm{a}_{\mathrm{W}}$ and $15{ }^{\circ} \mathrm{C}$ after 25 days of incubation for both strains. Overall, strain NRRL 66749 produced higher levels of T-2 and HT-2 than the other strain under the same conditions. These results overlap with those obtained by Kokkonen et al. [18], who demonstrated that F. sporotrichioides strains produced more T-2 + HT-2 toxins at $15{ }^{\circ} \mathrm{C}$ and $0.995 \mathrm{a}_{\mathrm{W}}$, while $F$. langsethiae produced the maximum at $25^{\circ} \mathrm{C}$ and $0.98 \mathrm{a}_{\mathrm{W}}$ in an oat-based media. Previous results of Kokkonen et al. [17] were obtained on a grain mixture where the conditions of $15^{\circ} \mathrm{C}$ and $0.995 \mathrm{a}_{\mathrm{W}}$ favoured the toxin production by both F. sporotrichioides and F. langsethiae. Based on their findings, they concluded that a w was the most important factor in controlling T-2 + HT-2 production, rather than temperature. As opposed to our study, the authors did not include $30{ }^{\circ} \mathrm{C}$ in their study because this temperature is not recorded in their country (Finland) during the cultivation of oats, wheat and barley, cereals in which F. langsethiae and F. sporotrichioides are responsible for the natural occurrence of type A trichothecenes. Medina and Magan [19] determined temperature and $\mathrm{a}_{\mathrm{W}}$ effects on the production of T-2 and HT- 2 by F. langsethiae strains from north European countries. Those authors included 30 and $35^{\circ} \mathrm{C}$ in their study and demonstrated that the optimal conditions of $\mathrm{a}_{\mathrm{W}}$ and temperature for T-2 were 0.98 and $20^{\circ} \mathrm{C}$, while for HT-2, they were 0.995 and $30^{\circ} \mathrm{C}$. 
Regarding BEA production, the present study showed that the highest level was obtained at $0.995 \mathrm{a}_{\mathrm{W}}$ and $25-30{ }^{\circ} \mathrm{C}$ after 5 days of incubation for both strains. In general, the maximum BEA production levels by both strains were observed at similar incubation conditions; however, strains showed different behaviour. Kokkonen et al. [17] studied the effect of culture conditions on BEA production by seven Fusarium species on a grain mixture (wheat, oats and barley) at three different $\mathrm{a}_{\mathrm{W}}$ and temperature combinations. The authors found that the maximum levels of this toxin for F. sporotrichioides occur at 0.96 aw and $25^{\circ} \mathrm{C}$, and also that $F$. poae produced the maximum levels under two different conditions, 0.995 at $15^{\circ} \mathrm{C}$, and 0.96 at $25^{\circ} \mathrm{C}$. Recently, increased importance has been given to the investigation of this mycotoxin in cereals because of its toxic effects on plants and animals [24].

Data obtained from two-dimensional profiles of $\mathrm{a}_{\mathrm{W}}$ by temperature interactions for F. chaquense allowed the recognition of areas where climate conditions could indicate a significant risk of grasses mycotoxin accumulation. It seems that mycotoxin production levels could be high not only when $F$. chaquense grows optimally but also when it grows under stress conditions. Moreover, it is important to remark the toxicological risk due to the possible interaction among the toxins detected because the simultaneous production of different toxic metabolites could imply additive and/or synergistic effects on target organisms. In addition, as F. chaquense is commonly associated with natural grasses in Argentina, the threat to animal health posed by this fungus should not be underestimated.

On the basis of our results, the climatic conditions that occur in the Chaco wetlands would be conducive for the development of $F$. chaquense and the production of mycotoxins. In addition, this species would appear to be very versatile, as it can grow and produce mycotoxins in a wide range of aw and temperatures, which would give it an adaptive advantage over other Fusarium species and this would explain its high frequency of isolation in natural grasses growing in this wetland ecosystem.

\section{Materials and Methods}

\subsection{Strains}

Two F. chaquense strains, NRRL 66748 and NRRL 66749, isolated from asymptomatic plants belonging to the Poaceae family, collected from Chaco wetland, Argentina, during July 2011, were used in this study. These isolates were characterised by molecular and morphological criteria; whole genome sequence is also available [1]. The strains are preserved in the UNRC culture collection as spore suspensions in $15 \%$ glycerol frozen at $-80{ }^{\circ} \mathrm{C}$. Moreover, both strains were deposited in the Agricultural Research Service Culture Collection, Peoria, IL, USA (NRRL number).

\subsection{Medium Preparation}

Milled grasses were prepared by pulverising a mixture of Paspalum and Panicum in a mill with a $1 \mathrm{~mm}^{2}$ mesh (Cyclotech, Foss Tecator, Höganäs, Sweden). Mixtures of $2 \%(w / v)$ milled grass in water were prepared, and $2 \%(w / v)$ agar was added. The $a_{W}$ of the basic medium was adjusted to $0.995,0.98,0.95,0.93$ and 0.91 by the addition of different amounts of glycerol [25]. The media were autoclaved at $120^{\circ} \mathrm{C}$ for $20 \mathrm{~min}$. Flasks of molten media were thoroughly shaken prior to pouring into $9 \mathrm{~cm}$ sterile Petri dishes. Using an Aqualab Series 3 (Decagon Devices, Inc., Pullman, WA, USA), the aw of representative samples (2 of each treatment) of media was checked. Uninoculated control plates were also prepared and measured at the end of the experiment in order to detect any significant deviation of the $\mathrm{a}_{\mathrm{W}}$.

\subsection{Inoculation, Incubation and Growth Assessment}

Petri plates were inoculated with a 3-mm-diameter agar disk taken from the margin of a 7-day-old colony of each isolate grown on synthetic nutrient agar [26] at $25^{\circ} \mathrm{C}$ and transferred face down to the center of each plate. Inoculated plates of the same $\mathrm{a}_{\mathrm{W}}$ were sealed in polyethylene bags and incubated at 15,25 and $30^{\circ} \mathrm{C}$ for 25 days. A full factorial design was used where the factors were $\mathrm{a}_{\mathrm{W}}$, temperature and strain, and the response was growth (total number of plates: $5 \mathrm{a}_{\mathrm{W}} \times 3$ temperatures $\times 2$ strains $\times 3$ replicates). 
For growth assessment, two diameters of the growing colonies were measured at right angles to each other every day for 25 days or until the colony reached the edge of the plate. Colonies radios were plotted against time, and linear regression was applied in order to obtain the growth rate ( $\mathrm{mm} /$ day) as the slope of the line. At the end of the incubation period, uninoculated controls and treatments were frozen for later extraction and mycotoxins determination.

\subsection{Mycotoxin Extraction}

For mycotoxin extraction, all control and treatment Petri plates were used. Mycotoxins were extracted with $50 \mathrm{~mL}$ of methanol-water $(90: 10, v / v)$ by shaking half of the culture media ( 10 g) and mycelia with the solvent for 60 min on an orbital shaker (150 rpm) and then filtering the extracts through a filter paper (No. 4; Whatman International Ltd., Maidstone, Kent, UK). An aliquot extract $(1 \mathrm{~mL})$ was transferred to an amber vial, evaporated to dryness at $50{ }^{\circ} \mathrm{C}$ under a moderate stream of nitrogen. Dry extracts were redissolved in $1 \mathrm{~mL}$ of acetonitrile: water $(50: 50, v / v)$ and preserved at $-20^{\circ} \mathrm{C}$ until HPLC analysis.

\subsection{Mycotoxin Analysis}

\subsubsection{Chemicals and Preparation of Standards}

Mycotoxin standards (purity > 99\%) were supplied by Sigma-Aldrich (Milan, Italy). All solvents (HPLC grade) were purchased from J. T. Baker (Deventer, The Netherlands). Water was of Milli-Q quality (Millipore, Bedford, MA, USA).

Mycotoxin stock solutions of T-2 and HT-2 toxins $(1 \mathrm{mg} / \mathrm{mL}$ each) were prepared by dissolving solid commercial toxins in acetonitrile (HPLC grade). A stock solution was prepared by mixing the simple toxin solutions and diluting them with acetonitrile into amber silanised vials to obtain a solution containing $20 \mu \mathrm{g} / \mathrm{mL}$ of each toxin. Aliquots of the stock solution were evaporated to dryness under a stream of nitrogen at $50{ }^{\circ} \mathrm{C}$. The residue was dissolved with water/acetonitrile $(80: 20, v / v)$ to obtain calibrated standard solutions at $0.05,0.10,0.20,0.40,1.00,2.00$ and $4.00 \mu \mathrm{g} / \mathrm{mL}$ of T-2 and HT-2 toxins.

Standards stock solution of BEA $(1 \mathrm{mg} / \mathrm{mL})$ were prepared by dissolving the solid commercial toxin standards in methanol into amber silanised vials to obtain a solution containing $100 \mu \mathrm{g} / \mathrm{mL}$ of toxin. Adequate amounts of the stock solution were dried under a nitrogen stream at $50{ }^{\circ} \mathrm{C}$ and reconstituted with methanol/water $(70: 30, v / v)$ to obtain calibrant standard solutions since 0.02 a $40.00 \mu \mathrm{g} / \mathrm{mL}$. Standard solutions were stored at $-20^{\circ} \mathrm{C}$ and warmed after.

\subsubsection{Determination of Type A Trichothecenes (T-2 and HT-2)}

Type A Trichothecenes were detected using the method previously described by Pascale et al. [27]. T-2 and HT-2 toxins analysis was performed using a UHPLC (Agilent UHPLC system, 1290 Series). Both data acquisition and instrument control were performed by LC Openlab software (Agilent). For chromatographic separation, a reversed-phase column of $\mathrm{C}_{18}(50 \times 2.1 \mathrm{~mm}$ i.d., $1.8 \mu \mathrm{m}$, ZORBAX Eclipse Plus $)$ was used. Analyses were performed in the gradient mode. Solvent $\mathrm{A}$ was water and solvent $\mathrm{B}$ acetonitrile. Gradient conditions were initiated by holding for the first 1.5 min with $30 \% \mathrm{~B}$, and then solvent $\mathrm{B}$ was linearly increased to $35 \%$ in $0.5 \mathrm{~min}$ and kept constant for $2 \mathrm{~min}$. The flow rate was $0.5 \mathrm{~mL} / \mathrm{min}$, and the injection volume was $10 \mu \mathrm{L}$. The column temperature was maintained at $50{ }^{\circ} \mathrm{C}$, and the detector was set at $202 \mathrm{~nm}$ wavelength. Retention times were $1.97 \mathrm{~min}$ and 4.9 min for HT-2 and T-2, respectively. The mycotoxins were quantified by comparing peak areas with calibration curves obtained with standard solutions. The detection limit (LOD) based on a signal-to-noise ratio of 3:1 for both toxins was $0.24 \mu \mathrm{g} / \mathrm{g}$.

\subsubsection{Determination of Beauvericin}

Beauvericin was detected using the method previously described by Prosperini et al. [28]. BEA analysis was performed using an HPLC (Agilent 1260 Series, Agilent Technology, Santa Clara, CA, USA) equipped with a binary solvent manager and a diode 
array (DAD). Both data acquisition and instrument control were performed by LC Openlab software (Agilent). For chromatographic separation, a reversed-phase column of $C_{18}$ $(150 \times 4.6 \mathrm{~mm}$ i.d., $5 \mu \mathrm{m}$, Gemini-Phenomenex, Torrance, CA, USA $)$ with a guard column SecurityGuard ${ }^{\mathrm{TM}}(4 \times 3.0 \mathrm{~mm})$ of the same material was used. Analyses were performed in the gradient mode. Solvent A was water and solvent B acetonitrile. Gradient conditions were initiated by holding for the first 5 min with $70 \%$, then solvent B was linearly increased to $90 \%$ in $10 \mathrm{~min}$ and kept constant for $1 \mathrm{~min}$. The column was re-equilibrated with $70 \%$ eluent B for $4 \mathrm{~min}$. The flow rate was $1.0 \mathrm{~mL} / \mathrm{min}$, and the injection volume was $100 \mu \mathrm{L}$. The column temperature was maintained at $40{ }^{\circ} \mathrm{C}$, and the detector was set at $205 \mathrm{~nm}$ wavelength, with a retention time of $11.4 \mathrm{~min}$. The mycotoxin was quantified by comparing peak areas with calibration curves obtained with standard solutions. The detection limit (LOD), based on a signal-to-noise ratio of 3:1, was $0.04 \mu \mathrm{g} / \mathrm{g}$.

A recovery experiment was performed in triplicate by spiking of the final working solution to obtain levels of $500 \mathrm{ng} / \mathrm{mL}$ of T-2, HT-2 and BEA $2 \%$ milled grass agar culture medium, previously sterilised and cooled to approximately $50^{\circ} \mathrm{C}$, then it was homogenised by shaking and distributed at a rate of $20 \mathrm{~mL}$ per Petri dish. Once the culture medium had solidified, the toxins were extracted, detected and quantified following the methodologies described above. The mean recovery was $99 \%, 98 \%$ and $98 \%$ for T-2, HT-2 and BEA, respectively.

\subsection{Statistical Analysis}

The growth rate, lag phase and mycotoxin concentration were evaluated by analysis of variance (ANOVA) using InfoStat version 2016 [29]. Statistical significance was determined at $p<0.01$.

Author Contributions: M.J.N. and E.C. performed the whole experiment, M.H. performed the analysis of the metabolites. M.L.R. and A.M.T. conceived and designed the experiments. M.L.R. and M.J.N. analysed the data and wrote the paper. M.L.R., A.M.T. and M.H. revised the manuscript. M.L.R. project administration and funding acquisition. All authors have read and agreed to the published version of the manuscript.

Funding: This work was supported by grants from Agencia Nacional de Promoción Científica y Tecnológica (MINCyT) through PICT-2019-2949-Prestamo BID.

Institutional Review Board Statement: Not applicable.

Informed Consent Statement: Not applicable.

Acknowledgments: Nichea M.J. is a fellow of CONICET and Ramirez M.L., Torres A.M. and Cendoya E. are members of the Research Career of CONICET.

Conflicts of Interest: The authors declare no conflict of interest.

\section{References}

1. Nichea, M.; Proctor, R.; Probyn, C.; Palacios, S.; Cendoya, E.; Sulyok, M.; Chulze, S.; Torres, A.; Ramirez, M. Fusarium chaquense sp. nov, a novel type A trichothecene-producing species from native grasses in a wetland ecosystem in Argentina. Mycologia 2021, in press. [CrossRef]

2. Yli-mattila, T.; Ward, T.J.; Donnell, K.O.; Proctor, R.H.; Burkin, A.A.; Kononenko, G.P.; Gavrilova, O.P.; Aoki, T.; McCormick, S.P.; Yu, T. Fusarium sibiricum sp. nov., a novel type A trichothecene-producing Fusarium from northern Asia closely related to F. sporotrichioides and F. langsethiae. Int. J. Food Microbiol. 2011, 147, 58-68. [CrossRef] [PubMed]

3. Rocha, L.O.; Laurence, M.H.; Proctor, R.H.; Mccormick, S.P.; Summerell, B.A.; Liew, E.C.Y. Variation in type A trichothecene production and trichothecene biosynthetic genes in Fusarium goolgardi from natural ecosystems of Australia. Toxins 2015, 7, 4577-4594. [CrossRef] [PubMed]

4. Nichea, M.; Palacios, S.; Chiacchiera, S.; Sulyok, M.; Krska, R.; Chulze, S.; Torres, A.; Ramirez, M. Presence of multiple mycotoxins and other fungal metabolites in native grasses from a wetland ecosystem in Argentina intended for grazing cattle. Toxins 2015, 7, 3309-3329. [CrossRef]

5. Laraba, I.; McCormick, S.P.; Vaughan, M.M.; Geiser, D.M.; O’Donnell, K. Phylogenetic diversity, trichothecene potential, and pathogenicity within Fusarium sambucinum species complex. PLoS ONE 2021, 16, e0245037. [CrossRef] [PubMed]

6. Agriopoulou, S.; Stamatelopoulou, E.; Varzakas, T. Advances in occurrence, importance, and mycotoxin control strategies: Prevention and detoxification in foods. Foods 2020, 9, 137. [CrossRef] [PubMed] 
7. Munkvold, G.P. Fusarium species and their associated mycotoxins. In Mycotoxigenic Fungi: Methods and Protocols; Moretti, A., Susca, A., Eds.; Humana Press: New York, NY, USA, 2017; pp. 51-106.

8. Proctor, R.H.; McCormick, S.P.; Gutiérrez, S. Genetic bases for variation in structure and biological activity of trichothecene toxins produced by diverse fungi. Appl. Microbiol. Biotechnol. 2020, 104, 5185-5199. [CrossRef] [PubMed]

9. McCormick, S.P.; Stanley, A.M.; Stover, N.A.; Alexander, N.J. Trichothecenes: From simple to complex mycotoxins. Toxins 2011, 3 , 802-814. [CrossRef] [PubMed]

10. Charmley, L.L.; Rosenberg, A.; Trenholm, H.L. Factors responsible for economic losses due to Fusarium mycotoxin contamination of grains, foods and feedstuffs. In Mycotoxins in Grains: Compounds Other than Aflatoxin; Miller, J.D., Trenholm, H.L., Eds.; Eagan Press: St. Paul, MI, USA, 1994; pp. 471-486.

11. Marin, S.; Magan, N.; Ramos, A.J.; Sanchis, V. Fumonisin-producing strains of Fusarium: A review of their ecophysiology. J. Food Prot. 2004, 67, 1792-1805. [CrossRef] [PubMed]

12. Leslie, J.F.; Zeller, K.A.; Logrieco, A.; Mule, G.; Moretti, A.; Ritieni, A. Species diversity of and toxin production by Gibberella fujikuroi species complex strains isolated from native prairie grasses in Kansas. Appl. Environ. Microbiol. 2004, 70, $2254-2262$. [CrossRef]

13. Phan, H.T.; Burgess, L.W.; Summerell, B.A.; Bullock, S.; Liew, E.C.Y.; Clarkson, J.R. Gibberella gaditjirrii (Fusarium gaditjirrii) sp. nov., a new species from tropical grasses in Australia. Stud. Mycol. 2004, 50, 261-272.

14. Sanchez Marquez, S.; Bills, G.F.; García Criado, B.; Zabalgogeazcoa, I. Diversity and structure of the fungal endophytic assemblages from two sympatric coastal grasses. Fungal. Divers. 2008, 33, 87-100.

15. Medina, A.; Magan, N. Comparisons of water activity and temperature impacts on growth of Fusarium langsethiae strains from northern Europe on oat-based media. Int. J. Food Microbiol. 2010, 142, 365-369. [CrossRef]

16. Mateo, J.J.; Mateo, R.; Jime, M. Accumulation of type A trichothecenes in maize, wheat and rice by Fusarium sporotrichioides isolates under diverse culture conditions. Int. J. Food Microbiol. 2002, 72, 115-123. [CrossRef]

17. Kokkonen, M.; Ojala, L.; Parikka, P.; Jestoi, M. Mycotoxin production of selected Fusarium species at different culture conditions. Int. J. Food Microbiol. 2010, 143, 17-25. [CrossRef] [PubMed]

18. Kokkonen, M.; Jestoi, M.; Laitila, A. Mycotoxin production of Fusarium langsethiae and Fusarium sporotrichioides on cereal-based substrates. Micotoxin Res. 2012, 28, 25-35. [CrossRef] [PubMed]

19. Medina, A.; Magan, N. Temperature and water activity effects on production of T-2 and HT-2 by Fusarium langsethiae strains from north European countries. Food Microbiol. 2011, 28, 392-398. [CrossRef]

20. Alberto, J.A. El Chaco oriental y sus fisonomías vegetales. Geográfica Digit. 2006, 3, 1-14. [CrossRef]

21. Langseth, W. Mycotoxin production and cytotoxicity of Fusarium strains isolated from Norwegian cereals. Mycopathologia 1998, 144, 103-113. [CrossRef] [PubMed]

22. Thrane, U.; Adler, A.; Clasen, P.E.; Galvano, F.; Langseth, W.; Lew, H.; Logrieco, A.; Nielsen, K.F.; Ritieni, A. Diversity in metabolite production by Fusarium langsethiae, Fusarium poae, and Fusarium sporotrichioides. Int. J. Food Microbiol. 2004, 95, 257-266. [CrossRef] [PubMed]

23. Jestoi, M.N.; Paavanen-Huhtala, S.; Parikka, P.; Yli-Mattila, T. In vitro and in vivo mycotoxin production of Fusarium species isolated from Finnish grains. Arch Phytopathol. Pflanzenschutz 2008, 41, 545-558. [CrossRef]

24. Jestoi, M. Emerging Fusarium-mycotoxins fusaproliferin, beauvericin, enniatins, and moniliformin-A review. Crit. Rev. Food Sci. Nut. 2008, 48, 21-49. [CrossRef] [PubMed]

25. Dallyn, H.; Fox, A. Spoilage of materials of reduced water activity by xerophilic fungi. In Microbial Growth and Survival in Extremes of Environment; Gould, G.H., Corry, J.E.L., Eds.; The Society for Applied Bacteriology, Technical Series Number 15; Academic Press: London, UK, 1980; Volume 3, pp. 129-139.

26. Gerlach, W.; Nirenberg, H. The Genus Fusarium - A Pictorial Atlas; Mitteilungen aus der Biologischen Bundesanstalt fur Land- und Forstwirtschaft Berlin-Dahlem; Kommissionsverlag P. Parey: Berlin, Germany, 1982; Volume 209, pp. 1-406.

27. Pascale, M.; Panzarini, G.; Visconti, A. Determination of HT-2 and T-2 toxins in oats and wheat by ultra-performance liquid chromatography with photodiode array detection. Talanta 2012, 89, 231-236. [CrossRef] [PubMed]

28. Prosperini, A.; Meca, G.; Font, G.; Ruiz, M.J. Study of the cytotoxic activity of beauvericin and fusaproliferin and bioavailability in vitro on Caco-2 cells. Food Chem. Toxicol. 2012, 50, 2356-2361. [CrossRef] [PubMed]

29. Di Rienzo, J.A.; Casanoves, F.; Balzarini, M.; Gonzalez, L.; Cuadroda, M.; Robledo, C. InfoStat Versión 2016; Grupo InfoStat, FCA, Universidad Nacional de Córdoba: Córdoba, Argentina, 2018. 